\title{
Problemy regeneracyjnego napawania stali średnio- i wysokowęglowych
}

\author{
Problems of restoration medium and high-carbon \\ steels by hard-facing
}

\section{Streszczenie}

Rozpatrzono zagadnienia odporności na zużycie w warunkach tarcia metal-metal warstw napawanych na podłoże wysokowęglowe. Wykazano, ze korelacja między twardością i odpornością na zużycie występuje nie we wszystkich stalach węglowych i austenitycznych materiałów. Stwierdzono, że materiały austenityczne pod względem odporności na zużycie przewyższają węglowe i są bardziej odpowiednie przy regeneracji powierzchni tarcia także pod względem technologii.

\section{Wstęp}

Stal konstrukcyjna węglowa o duzej wytrzymałości, odporności na zużycie, wysokej właściwości sprężystej gatunków 60,60G, 65, 65G, 70, 70G, 75, 80 i 85 jest stosowana po hartowaniu i odpuszczaniu do wytwarzania części pracujących w warunkach tarcia i oddziaływania wysokich obciążeń statycznych i wibracyjnych (tarcze sprzęgłowe, mimośrody, wrzeciona, walce, obręcze kół wagonów tramwajowych, koła suwnicowe, zawory wylotowe kompresorów), a także zużycia ściernego i obciążeń udarowych (części układów napędowych i kruszarek, zęby bron, pługi, noże).

Podstawowym składnikiem stopowym, określającym strukturę, właściwości i przeznaczenie tych stali jest węgiel. Zwiększenie zawartości węgla zapewnia szczególne właściwości materiałom, łącząc wysoką wytrzymałość, twardość i odporność na zużycie. Właśnie dlatego wysokowęglowe stale (o zawartości węgla $\geq 0,5 \%$ ) są najbardziej rozpowszechnione w budowie maszyn, transporcie, narzędziowniach, tłocznictwie i innych gałęziach przemysłu.

Prof. dr hab. inż. W.D. Kuzniecow, inż. P.W. Popowicz - Politechnika Kijowska, Ukraina.
Regeneracja zużytych powierzchni części maszyn i konstrukcji ze stali wysokowęglowych napotyka znaczne trudności. Przy oddziaływaniu źródła ciepła podczas napawania regeneracyjnego powierzchni zachodzą przemiany polimorficzne z powstawaniem struktur martenzytycznych. Tworzeniu takich struktur towarzyszą zmiany objętościowe w materiale i w następstwie naprężenia strukturalne, które sumują się $z$ naprężeniami cieplnymi powstającymi wskutek oddziaływania spawalniczego źródła ciepła. Zwiększony poziom naprężeń jest podstawową przyczyną powstawania pęknięć zimnych w różnych strefach warstwy napawanej i podłoża.

Podstawową metodą zapobiegania pęknięciom zimnym jest podgrzewanie wstępne lub podgrzewanie w czasie spawania, ponieważ zmniejszenie prędkości stygnięcia pozwala na uzyskanie mniej twardych struktur przejściowych bainitu, sorbitu, troostytu.

Przy regeneracji części maszyn i konstrukcji ze stali wysokowęglowych można wykorzystać zalecenia literaturowe. W pracy [1] na podstawie analizy dokumentu II-1303-96 (IIE-221-96) Międzynarodowego Instytutu Spawalnictwa System klasyfikacji stopów do napawania utwardzającego podano zalecenia dotyczące wyboru materiałów na podstawie klasyfikacji ich składu chemicznego i mikrostruktury. Wydzielono podstawowe grupy strukturalne i wprowadzono ich oznaczenia, 
Tablica I. Podstawowe charakterystyki i obszar zastosowań materiałów do napawania

Table I. Basic characteristics and applications of materials for hard-facing

\begin{tabular}{|c|c|c|c|c|}
\hline \multirow{2}{*}{ Wskaźnik } & \multicolumn{4}{|c|}{ Grupa strukturalna materiałów do napawania } \\
\hline & MK1 & A2 & A3 & A2K, A3K \\
\hline $\begin{array}{l}\text { Skład } \\
\text { chemiczny, \% }\end{array}$ & $\begin{array}{l}(0,5 \div 1,5) \% \mathrm{C}, \mathrm{Cr}+\mathrm{W}+\mathrm{Mo}- \\
+\mathrm{V}(\mathrm{Co})=7 \div 16 \%\end{array}$ & $\begin{array}{l}(0,7 \div 1,2) \% \mathrm{C}, \mathrm{Mn}+\mathrm{Cr}+\mathrm{Ni}=13 \div 25 \% \\
\text { zwykle } 12 \div 14 \%(\mathrm{Mn}+\mathrm{Cr}) \text { i lub } \mathrm{Ni}\end{array}$ & $\begin{array}{l}(0,5 \div 0,7) \% \mathrm{C} \\
\mathrm{Mn}+\mathrm{Cr}=25 \div 35 \%\end{array}$ & $\begin{array}{l}(0,9 \div 1,7) \% C \\
M n+C r+N=15 \div 30 \%\end{array}$ \\
\hline Mikrostruktura & $\begin{array}{l}\text { martenzyt z siatką węgli- } \\
\text { ków po napawaniu, możli- } \\
\text { wa niewielka ilość austenitu } \\
\text { szczątkowego }\end{array}$ & $\begin{array}{l}\text { austenit lub austenit umocniony } \\
\text { węglikami, obróbka cieplna pro- } \\
\text { wadzi do kruchości }\end{array}$ & $\begin{array}{l}\text { austenit, obróbka ciepl- } \\
\text { na niepożądana }\end{array}$ & $\begin{array}{l}\text { austenit z węglikami } \\
\text { o dużym stopniu } \\
\text { rozproszenia }\end{array}$ \\
\hline Twardość & $\begin{array}{l}55 \div 62 \text { HRC po napawa- } \\
\text { niu, odpuszczanie w } 750^{\circ} \mathrm{C} \\
\text { w ciągu } 4,5 \text { h obniża twar- } \\
\text { dość }\end{array}$ & ok. $200 \mathrm{HB}$ po napawaniu & $\begin{array}{l}\text { ok. } 200 \mathrm{HB} \\
\text { po napawaniu }\end{array}$ & $\begin{array}{l}250 \div 300 \mathrm{HB} \text { po napa- } \\
\text { waniu, podczas pracy } \\
\text { następuje umocnienie } \\
\text { do } 45 \mathrm{HRC}\end{array}$ \\
\hline $\begin{array}{l}\text { Odporność } \\
\text { na udary }\end{array}$ & wysoka & wysoka & wysoka & wysoka \\
\hline $\begin{array}{l}\text { Odporność na } \\
\text { tarcie metal-metal }\end{array}$ & wysoka & wysoka & wysoka & wysoka \\
\hline $\begin{array}{l}\text { Obszar } \\
\text { zastosowań }\end{array}$ & $\begin{array}{l}\text { warzędzia do pracy na gorą- } \\
\text { co }\left(\mathrm{T} \leq 500^{\circ} \mathrm{C}\right) \text { : noże do cię- } \\
\text { cia drutu, narzędzie skrawa- } \\
\text { jące itd. }\end{array}$ & $\begin{array}{l}\text { napawanie elementów pracu- } \\
\text { jących w warunkach tarcia me- } \\
\text { tal-metal lub zużycia ścierne- } \\
\text { go w połączeniu z obciążeniem } \\
\text { udarowym }\end{array}$ & $\begin{array}{l}\text { elementy pracujące } \\
\text { w warunkach wysokich } \\
\text { obciążeń udarowych } \\
\text { i tarcia metal-metal. }\end{array}$ & $\begin{array}{l}\text { elementy pracujące } \\
\text { w warunkach wysokich } \\
\text { obciążeń udarowych } \\
\text { w połączeniu ze zuży- } \\
\text { ciem ściernym dużymi } \\
\text { cząsteczkami }\end{array}$ \\
\hline
\end{tabular}

w szczególności: ferryt umocniony fazą wtórną - FWt; martenzyt M1, M2, M3, M4 w zależności od zawartości węgla i dodatków stopowych; martenzyt umocniony węglikami MK1, MK2, MEK, MOK; austenit typu A1 (Cr, Ni); austenit + ferryt typu AF; austenit manganowy typu A2; austenit chromowo-manganowy $A 3$; austenit umocniony węglikami A2K, A3K, AOK, AEK, AKK [1].

W tablicy I przytoczono wyciąg $z$ charakterystykami grup strukturalnych, które są zalecane do napawania warstw odpornych na zużycie ścierne dla warunków obciążeń udarowych i tarcia metal-metal.

Dane w tablicy I świadczą o tym, że możliwy skład chemiczny stopów wymienionych grup strukturalnych ma stosunkowo szeroki zakres zmian. Nie pozwala to na jednoznaczne określenie składu chemicznego nawet dla wyodrębnionej grupy strukturalnej.

Można także przy ich regeneracji skorzystać z zaleceń normy EN 14700 Materiały dodatkowe do spawania - Materiały dodatkowe do napawania utwardzającego, która dotyczy napawania powierzchni elementów nowych oraz naprawy metodą napawania elementów, które powinny charakteryzować się odpornością na oddziaływanie mechaniczne, chemiczne, cieplne lub ich łączny wplyw [2]. Norma określa wymagania dotyczące klasyfikacji materiałów do napawania na podstawie składu chemicznego stopiwa, a także zawiera dane dotyczące właściwości stopów różnych typów, ich struktury i twardości oraz zalecenia dotyczące stosowania.

Brak jednolitych metod badania odporności na zużycie nie pozwala obecnie na przedstawienie właściwości określonych w tej normie (mechanicznych, cieplnych itd.) za pomocą kryteriów ilościowych. W związku z tym w odniesieniu do zużycia w warunkach tarcia metal-metal oraz innych rodzajów zużycia aktualne jest gromadzenie eksperymentalnych danych w ramach składów chemicznych stopów, które są zalecane dla danego rodzaju zużycia.
Celem pracy jest ocena odporności na zużycie materiałów do napawania zalecanych ze względu na skład chemiczny i strukturę do pracy w warunkach tarcia metal-metal.

Według [1, 2] stosunkowo wysoką odporność na zużycie w warunkach tarcia metal-metal przy występowaniu obciążeń zapewniają materiały o matrycy martenzytycznej, umocnionej węglikami, a także z metastabilną strukturą austenitu manganowego i chromowo-manganowego, skłonnego do umocnienia odkształceniowego i utwardzenia wskutek przemian fazowych.

Otrzymanie takich struktur, szczególnie przy regeneracyjnym napawaniu zużytych powierzchni, zależy nie tylko od składu chemicznego materiałów dodatkowych do napawania, ale także od warunków chłodzenia. Ten czynnik uwzględniano podczas badań, stosując do napawania zarówno elektrody otulone, jak i druty proszkowe.

\section{Przebieg i wyniki badań}

Struktury martenzytyczne i austenityczne otrzymywano przez dobór materiałów dodatkowych do napawania $i$ energii liniowej napawania. Przy napawaniu kompozycji austenitycznych stosowano zalecenia zawarte w pracy [3]. Skład chemiczny doświadczalnych napoin podano $w$ tablicy II.

Badania odporności na zużycie przeprowadzano na urządzeniu do badania ścieralności M-22 wg schematu wał-klocek. Zastosowano próbki o długości $20 \mathrm{~mm}$ i szerokości $10 \mathrm{~mm} \mathrm{z}$ walcowym rowkiem w postaci segmentu o promieniu $20 \mathrm{~mm}$ i cięciwie $20 \mathrm{~mm}$. Jako przeciwpróbkę wykorzystano tarczę o średnicy $40 \mathrm{~mm}$, wykonaną ze stali 75 o twardości $300 \div 350 \mathrm{HB}$.

Warunki badań: nacisk na próbkę $p=0,5 \pm 0,1 \mathrm{MPa}$; prędkość tarcia $\mathrm{v}=3 \pm 0,25 \mathrm{~m} / \mathrm{s}$; temperatura badań $\mathrm{T}=60 \pm 20^{\circ} \mathrm{C}$; czas trwania badania $\mathrm{t}=1 \mathrm{~h}$. 
Tablica II. Skład chemiczny stopiwa

Table II. Chemical composition of weld metal

\begin{tabular}{|c|c|c|c|c|c|c|c|c|c|}
\hline \multirow{2}{*}{ 之 $\frac{\frac{\pi}{3}}{\frac{0}{\omega}}$} & \multicolumn{9}{|c|}{ Zawartość pierwiastków, \% wag. } \\
\hline & C & $\mathrm{Cr}$ & $\mathrm{Mn}$ & $\mathrm{Ni}$ & Si & Mo & V & $\mathrm{Ti}$ & $\mathrm{Cu}$ \\
\hline ' & 0,7 & 0,05 & 0,89 & 0,04 & 0,25 & - & - & - & - \\
\hline 30 & 0,5 & 1,1 & 0,8 & 1,7 & 0,43 & 0,5 & - & 0,4 & - \\
\hline 10 & 0,62 & 20,8 & 9 & 2 & 0,55 & 0,5 & - & - & 0,17 \\
\hline 23 & 0,27 & 4,5 & 5 & - & 0,2 & - & - & 0,08 & \\
\hline 26 & 0,5 & 0,2 & 11 & 0,08 & 0,8 & 0,3 & - & - & - \\
\hline 9 & 0,22 & 13 & 5,8 & 6 & 0,6 & 1,4 & 0,4 & - & 0,9 \\
\hline 7 & 0.11 & 11 & 10 & & & & & 0,8 & \\
\hline
\end{tabular}

Próbki ważono przed i po badaniu na wadze laboratoryjnej z dokładnością $0,0001 \mathrm{~g}$. Zużycie wagowe określano jako różnicę masy $(\Delta \mathrm{m})$ próbki przed próbą tarcia i po badaniu. Równolegle mierzono twardość jako jeden ze wskaźników stosowanych w dokumentacji technicznej regeneracji, jakościowo charakteryzujący odporność na zużycie.

Badaniom poddano otrzymane metastabilne struktury austenityczne, struktury sorbitu hartowania i drobnoiglastego martenzytu w matrycy austenitycznej, a także martenzytu. Wyniki badań napawanych próbek przytoczono w tablicy III.

Wyniki badań wykazały, że bezpośrednia zależność między twardością i odpornością na zużycie występuje nie we wszystkich przypadkach, zarówno dla kompozycji węglowych, jak i austenitycznych.

Przykładowo struktura martenzytyczno-bainityczna ma mniejszą odporność na zużycie $(\Delta \mathrm{m}=0,08 \mathrm{~g})$ przy podwyższonej twardości (42 HRC) względem podłoża (32 HRC). Austenityczna struktura z twardą składową (austenit + sorbit hartowania) przy takich samych wartościach twardości (42 HRC), jak i struktura martenzytyczno-bainityczna, ma odporność na zużycie $(\Delta \mathrm{m}=0,11 \mathrm{~g})$, bliską wysokowęglowemu podłożu $(\Delta \mathrm{m}=0,12 \mathrm{~g})$.

Austenityczne kompozycje z twardą składową (austenit + drobnoiglasty martenzyt) w porównaniu z podłożem wysokowęglowym przy praktycznie jednakowej twardości $(31 \div 32 \mathrm{HRC})$ mogą mieć pięciokrotnie wyższą odporność na zużycie $(\Delta \mathrm{m}=0,022 \mathrm{~g})$ i odwrotnie, przy większej twardości (austenit + sorbit hartowania) - odporność na zużycie praktycznie jednakową z podłożem.

Tablica III. Wyniki badań napawanych kompozycji

Table III. Examination results of material compositions hard-facing

\begin{tabular}{|c|c|c|c|}
\hline $\begin{array}{c}\mathrm{Nr} \\
\text { stopiwa }\end{array}$ & Struktura & $\begin{array}{c}\text { Twardość, HRC } \\
\text { przeciwciało/próbka }\end{array}$ & $\begin{array}{c}\text { Zużycie, } \\
\Delta \mathrm{m}, \mathrm{g}\end{array}$ \\
\hline 24 & podłoże - sorbit & $30 / 32$ & 0,12 \\
\hline 30 & martenzyt + bainit & $30 / 42$ & 0,08 \\
\hline 23 & $\begin{array}{c}\text { austenit + sorbit } \\
\text { hartowania }\end{array}$ & $30 / 42$ & 0,11 \\
\hline 10 & $\begin{array}{c}\text { austenit + marten- } \\
\text { zyt drobnoiglasty }\end{array}$ & $30 / 31$ & 0,022 \\
\hline 7 & $\begin{array}{c}\text { austenit chromo- } \\
\text { wo-manganowy }\end{array}$ & $30 / 28$ & 0,05 \\
\hline 9 & $\begin{array}{c}\text { austenit chromo- } \\
\text { wo-niklowo-man- } \\
\text { ganowy }\end{array}$ & $30 / 15$ & 0,11 \\
\hline 26 & $\begin{array}{c}\text { austenit wysoko- } \\
\text { manganowy }\end{array}$ & $30 / 13$ & 065 \\
\hline
\end{tabular}

Chromowo-niklowo-manganowa kompozycja ma dwukrotnie wyższą odporność na zużycie $(\Delta \mathrm{m}=0,065 \mathrm{~g})$, niż wysokomanganowa $(\Delta \mathrm{m}=0,11 \mathrm{~g})$, przy praktycznie nieznacznej jednakowej twardości początkowej $(13 \div 15)$ HRC.

Stwierdzone właściwości metastabilnych struktur austenitycznych mogą być wynikiem tego, że w przyjętych warunkach badań odporności na zużycie kompozycje chromowo-niklowo-manganowa i chromowomanganowa wykazują skłonność do umocnienia odkształceniowego i utwardzenia wskutek przemian fazowych. Kompozycja manganowa w tych warunkach takiej skłonności nie wykazuje i otrzymane wyniki odzwierciedlają wartości odporności na zużycie w stanie wyjściowym po napawaniu.

Na rysunku 1 przedstawiono niektóre z badanych struktur typu martenzytycznego i austenitycznego.

Struktura sorbitu hartowania (rys. 1a) odpowiada materiałowi podłoża (stal R75 w stanie dostawy). Struktura przedstawiona na rysunku $1 \mathrm{~b}$ stanowi kompozycję bainityczno-martenzytyczną (tabl. II, stopiwo 30). Struktura pokazana na rysunku $1 \mathrm{c}$ to chromowo-manganowy austenit (tabl. II, stopiwo 7). Struktura przedstawiona na rysunku $1 \mathrm{~d}$ stanowi drobnoiglasty martenzyt w matrycy austenitycznej.

Struktury martenzytyczne pod względem twardości i odporności na zużycie mają wyższe wskaźniki niż wysokowęglowe podłoże, jednak przy napawaniu takiej kompozycji w ściegach pojawiają się pęknięcia, w związku z czym niemożliwe jest ich stosowanie bez podgrzewania wstępnego.

Przy napawaniu kompozycji austenitycznych nie obserwuje się powstawania pęknięć w ściegach i strefie przyspoinowej.

Wyniki badań odporności na zużycie potwierdzane są danymi analizy fraktogramów powierzchni tarcia (rys. 2). Dla metastabilnego austenitu powierzchnia tarcia ma jednorodną mikrogeometrię powierzchni bez śladów wykruszania i charakterystycznej struktury bruzdowej powstającej w wyniku plastycznego odsuwania materiału z powierzchni tarcia przez cząstki ścierające.

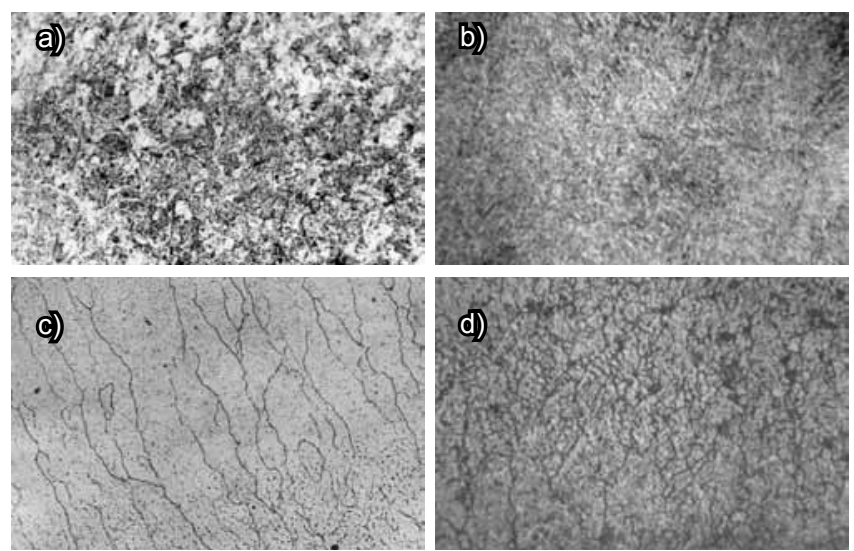

Rys. 1. Mikrostruktury podłoża i napawanych kompozycji (300x) Fig. 1. Microstructures of substrat and metal compositions hard-facing (300x) 
Charakterystyczną cechą morfologiczna powierzchni tarcia matrycy austenitycznej ze składnikiem twardym jest występowanie bruzd, których wymiary geometryczne zmieniają się w szerokim zakresie, co świadczy o niejednorodności struktury i odpowiednio o odporności na zużycie strukturalnych składowych kompozycji stopiwa.

Największy efekt wzrostu odporności na zużycie napawanego materiału $\mathrm{w}$ porównaniu $\mathrm{z}$ wysokowęglowym podłożem obserwuje się w kompozycjach austenitu chromowo-manganowego i chromowo-niklowo-manganowego, a także austenitu $z$ drobnoiglastym martenzytem, dzięki czemu są bardziej przydatne do regeneracji powierzchni elementów pracujących w warunkach tarcia ślizgowego i działania obciążeń. Dane te są zgodne z wynikami pracy [4] dotyczącej badań analogicznego materiału podstawowego i materiałów klasy ferrytycznej oraz austenitycznej.

Otrzymane wyniki i wnioski zostały sprawdzone przy regeneracji rozjazdów (iglic) kolejowych. Miały one znaczne zużycie boczne (do $18 \mathrm{~mm}$ ) i dużą ilość pęknięć zmęczeniowych, które usuwano za pomocą wycinania mechanicznego.

Napawanie ściegów na iglicach prowadzono nanosząc je kolejno od dolnej części główki szyny do powierzchni jezdnej. Uwzględniając zmienne rozmiary
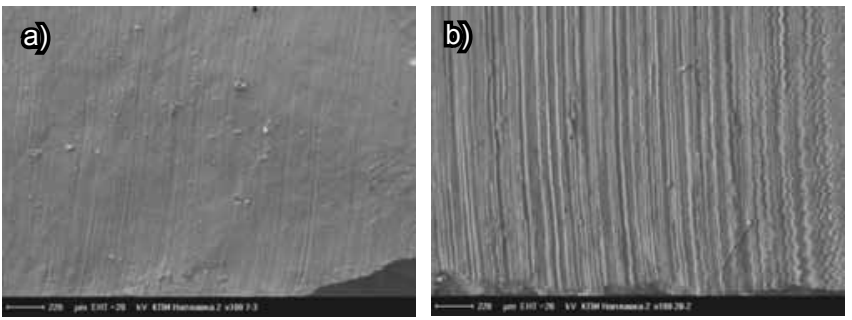

Rys. 2. Fraktogramy powierzchni tarcia: a) chromowo-manganowy austenit, b) sorbit hartowania w matrycy austenitycznej, pow. 100x

Fig. 2. Fractograph of friction surfaces: a) chromium-manganese austenite b) sorbitol hardening austenitic matrix, magn. 100x zużycia bocznego na wysokości główki szyny, pierwsze ściegi napawano, stosując następujące parametry: I $=350 \mathrm{~A} ; \mathrm{U}=32 \mathrm{~V} ; \mathrm{V}_{\text {nap }}=18 \mathrm{~m} / \mathrm{h}$; a przy układaniu kolejnych ściegów parametry: I $=400 \mathrm{~A} ; \mathrm{U}=34 \mathrm{~V}$; $\mathrm{V}_{\text {nap }}=18 \mathrm{~m} / \mathrm{h}$. W związku ze znaczną długością iglic (do $6 \mathrm{~m}$ ) napawanie prowadzono odcinkami. Stosowano topnik AN-26P. Orientacyjny skład chemiczny stopiwa: $13 \% \mathrm{Cr} ; 13 \% \mathrm{Mn} ; 2 \% \mathrm{Ni} ; 1 \% \mathrm{Mo} ; 1 \% \mathrm{~V}$.

Na rysunku 3a pokazano pierwszy napawany ścieg, a na rysunku $3 b$ - proces napawania kolejnego ściegu.

W napawanych bez podgrzewania wstępnego na wysokowęglowe podłoże ściegach o strukturze austenitu chromowo-manganowego nie występowały pęknięcia ani w warstwie napawanej, ani w strefie wpływu ciepła.

Napawane iglice zostały umieszczone na odcinku trasy kolejowej między stacjami Kijów - Browary.
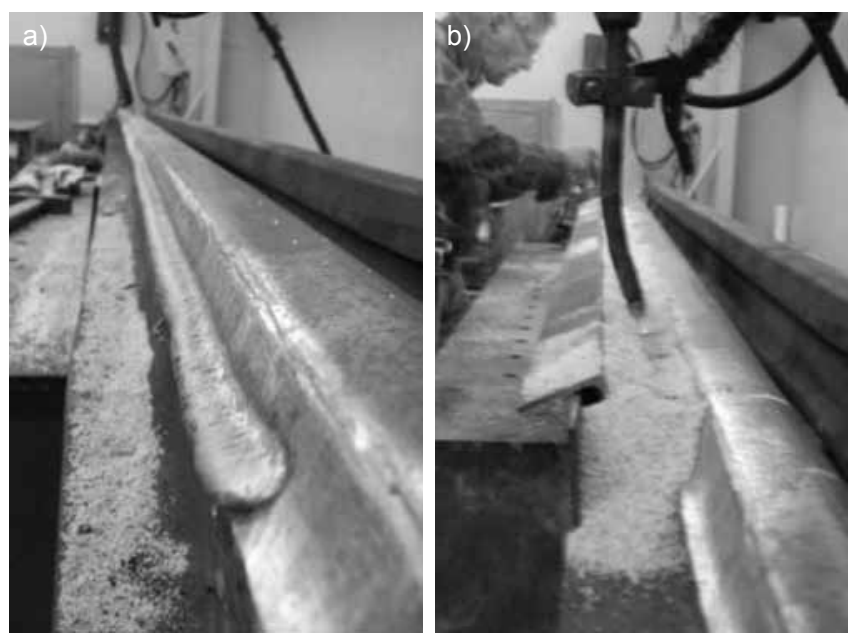

Rys. 3. Napawanie: a) pierwszego ściegu, b) proces układania kolejnego ściegu

Fig. 3. The view of first bead (a) and the process of second bead laying (b)

\section{Wnioski}

Metastabilne kompozycje austenityczne maja wyższą odporność na zużycie w porównaniu ze stalami wysokowęglowymi (w tym martenzytycznymi), co stanowi o ich lepszej przydatności regeneracji powierzchni elementów pracujących w warunkach tarcia i działania obciążeń.

\section{Literatura}

[1] Мазель Ю.А., Кусков Ю.В., Полищук Г. Н.: Классификация сплавов на основе железа для восстановительной и упрочняющей наплавки. Сварочное производство. 1999. № 4, s. 35-38.

[2] Рябцев И.А., Проценко Н.А.: Гармонизация стандартов на наплавочные материалы в соответствии с требованиями европейского стандарта EN 14700 «Сварочные материалы - Сварочные материалы для наплавки». Сварщик, 2007. № 5, s. 30-36.

[3] Каленский В.К., Черняк Я.П., Васильев В.Г., Соломийчук
Т.Г. Влияние погонной энергии на образование отколов в ЗТВ высокоуглеродистой стали М76 при наплавке аустенитными проволоками. Автоматическая сварка. 2001. №11, s. 11-14.

[4] Черняк Я.П. Сравнительная оценка износостойкости электродных материалов, применяемых для восстановления трамвайных рельсов. Автоматическая сварка. 2007. № 12, s. 41-43.

${ }^{*}$ W pracy brali udział dr inż. W.A. Makowiej, dr inż. S.M. Getmaniec $i$ inż. D.W. Stiepanow. 